\title{
LEI No 6.404/76: UMA ANÁLISE DOS PRINCIPAIS AVANÇOS PROPORCIONADOS À CONTABILIDADE NO BRASIL ${ }^{1}$
}

\section{LAW 6.404/76: AN ANALYSIS OF THE MAJOR ADVANCEMENTS MADE TO ACCOUNTING IN BRAZIL.}

\section{LEY 6.404/76: UN ANÁLISIS DE LOS PRINCIPALES AVANCES REALIZADOS EN CONTABILIDAD EN BRASIL.}

Mayse dos Reis Araujo, Graduanda em Ciências Contábeis pela Universidade de Brasília (UnB). Telefone: (061) 32538750. E-mail: mayse_ra@hotmail.com.

Maria Luiza Bomtempo de Oliveira Horn Pureza, Bacharel em Ciências Contábeis pela Universidade de Brasília (UnB). Telefone: (061) 96970505. E-mail: marialuiza_pureza@hotmail.com.

César Augusto Tibúrcio Silva, Doutor em Contabilidade pela Universidade de São Paulo. Professor Titular da Universidade de Brasília. Fone: 6133070610 e-mail:

cesartiburcio@unb.br.

\section{RESUMO}

Desde a colonização do Brasil, tentou-se criar normas que estabelecessem a Contabilidade no país, mas outras legislações sempre interferiram nessa área. Este estudo buscou mostrar as inovações trazidas pela Lei 6.404/76 na contabilidade brasileira, como resultado da globalização dos mercados, harmonização normativa e influência norte-americana, mas que poucas vezes, na literatura, foi evidenciado o que essa lei tinha de novo e como revolucionou a forma de se produzir as informações aos usuários. Para a constatação da importância da lei, foi utilizada como método a revisão bibliográfica, que teve como objetivo levantar todo o histórico e obras publicadas que tivessem como assunto principal esta norma, tendo destaque a primeira edição do Manual de Contabilidade da Sociedade por Ações de 1978, que mostra o que foi alterado a partir do texto normativo. Dessa forma, foi possível enxergar como foram criados métodos e demonstrações contábeis, que permitiram maior produção de informação, e como os usuários da informação passaram a ter um papel de destaque na Contabilidade no Brasil. Foi possível entender também como o país conseguiu passar maior credibilidade para seus investidores e para as empresas que aqui funcionavam.

Palavras-chave: Lei 6.404; História da Contabilidade; Contabilidade Societária.

\section{ABSTRACT}

Since the Brazil colonization, people have been trying to create rules to establish accounting activities in the country, but other legislations always interfered in this area. This study

\footnotetext{
${ }^{1}$ Artigo submetido em 08/04/2014, revisado em 12/01/2015, aceito em 05/05/2015 e divulgado em 31/12/2015 pelo Editor João Carlos Hipólito Bernardes do Nascimento, após double blind review.
} 
intends to show the innovations brought by the law 6.404/76 to Brazilian Accounting, as a result from the globalization of the markets, normative adjustment and North-American influence, although a few times, in literature, it got evident what this law had as news and how that revolutionized the way to produce information to users. In order to prove the importance of the law, the method used was bibliographic review, which had the objective to gather all the historic and published works that had this law as their main issue. Giving focus to the first edition of "Manual de Contabilidade das Sociedades por Ações" from 1978, that shows what had been altered since the normative text. Thereby, it was possible to note how methods and accounting demonstrations were created, which allowed higher levels of information production and how information users began to occupy highlighted positions in Brazil's Accounting. It was also possible to understand how the country could show more credibility to its investors and to the companies that used to operate here.

Keywords: Law 6.404; Accounting's history; Corporate Accounting.

\section{RESUMEN}

Desde la colonización del Brasil, se intentó crear normas que establecieran la Contabilidad en el país, sin embargo otras leyes siempre interfirieron en esta área. Este estudio buscó apuntar las inovaciones traídas por La Lei 6.404/76 en la Contabilidad brasileña, como resultado de la globalización de los mercados, armonización normativa e influencia norte americana, pero que pocas veces, en la literatura, fue evidenciado lo que esta ley tenia de nuevo y como revolucionó la manera de reproducir las informaciones a los usuarios. Para comprobar la importancia de la ley, fue utilizado como método la revisión bibliográfica, que tuvo como objetivo recoger todo el histórico y las obras publicadas que tuvieron como tema principal esta ley, destacando la primera edición del Manual de Contabilidade das Sociedades por Ações de 1978, que apunta lo que fue alterado a partir del texto normativo.De esta manera, fue posible ver como fueron creados los métodos y las demonstraciones cantabiles, que permitieron uma mayor producción de informaciones, y como los usuarios de la información pasaron a tener un papel de destaque en la Contabilidad en el Brasil. Fue posible entender también como el país logro transmitir mayor credibilidad a sus investidores y a las empresas que aqui funcionabam.

Palabras clave: Ley 6.404; Historia de Contabilidad; Contabilidad Corporativa.

\section{INTRODUÇÃO}

$\mathrm{A}$ base da legislação societária brasileira encontra-se na Lei 6.404, aprovada no final do ano de 1976. A literatura contábil cita extensamente esta lei, particularmente aqueles artigos relacionados com a área. Uma pesquisa realizada no Google Scholar com o termo "Lei 6.404" trouxe 3.420 resultados. Apesar disto, pouco se tem discutido sobre o papel histórico desta legislação para a contabilidade, conforme será demonstrado neste artigo. Os textos concentram-se em aspectos específicos da lei ou, mais recentemente, a alteração promovida pela Lei 11.638, que atualizou alguns dispositivos desta norma.

Antes da Lei 6.404, a legislação societária era regida pelo Decreto-Lei 2.627/1940. Este decreto estabeleceu a definição, constituição, liquidação, fusão, bem como os detalhamentos mais precisos da elaboração de demonstrativos contábeis (COELHO; LINS, 2010). Esse decreto já se encontrava defasado, na ocasião da promulgação da Lei 6.404, por GєECont, v.2, n. 2, Floriano-PI, Jul-Dez. 2015. 
isso se tornou imprescindível a elaboração de uma norma mais adequada a atender as necessidades empresariais e financeiras.

A Lei 6.404 propôs alterações substanciais na estrutura contábil em relação à estrutura normativa existente da época. Isto era condizente com o crescimento do mercado de capitais brasileiro, a tentativa de criar uma estrutura legal de negócios para o nosso país e a necessidade de atualizar o arcabouço legal face as mudanças ocorridas no ambiente externo. Segundo Geron (2008), marca a origem da normatização contábil no Brasil.

Dessa forma, dada a sua relevância, é importante uma investigação sobre o que a Lei 6.404 representou em termos de inovação para a contabilidade. Neste aspecto, o estudo está sustentado na seguinte problemática: quais os principais avanços que a Lei $n^{\circ}$ 6.404/76 trouxe em relação às normas anteriores? Portanto, o objetivo desse estudo foi investigar quais avanços propostos pela Lei $6.404 / 76$ para a contabilidade brasileira, em relação à legislação anterior.

Para responder a pergunta de pesquisa, realizou-se uma pesquisa documental. A pesquisa documental é aquela realizada tendo como fontes documentos (SANTOS, 2000). Foram utilizados documentos históricos na Biblioteca Nacional de Portugual e, principalmente, na Hemeroteca Digital Brasileira da Biblioteca Nacional. Além disto, utilizou-se também a série histórica do jornal O Estado de São Paulo. A razão da escolha deste jornal decorre da extensão da série histórica, iniciada no século XIX. Já a utilização de jornais foi uma opção metodológica dos autores visto que, em 1976, não existiam periódicos científicos em contabilidade no Brasil.

Outra fonte de pesquisa foi a primeira edição do Manual de Contabilidade das Sociedades por Ações, em 1978. Esta obra é a maior referência em contabilidade societária brasileira e foi lançada justamente após a aprovação da Lei 6.404. Ao longo desta primeira edição, os autores abordam algumas das principais inovações da lei.

Este artigo está dividido em seis partes, incluindo esta introdução, onde se encontra a justificativa e relevância do tema, o objetivo e o método de pesquisa. A seguir é realizada uma contextualização histórica sobre o desenvolvimento da normatização contábil no Brasil. A terceira parte diz respeito ao arcabouço conceitual das alterações. A seguir, discute-se o contexto estrutural da época em que a Lei 6.404 foi aprovada. As principais inovações trazidas pela Lei são objeto da quinta parte. O estudo finaliza com as considerações finais.

\section{FUNDAMENTAÇÃO TEÓRICA}

\subsection{Breve Evolução Histórica da Contabilidade Anterior À Lei 6.404}

O grande marco histórico da contabilidade foi a publicação do livro Summa de arithmetica, geometria, proportioni et proportionalità, em 1494, de autoria de Luca Pacioli. Apesar de ser um livro de matemática, a obra trazia um capítulo onde informava sobre o método das partidas dobradas, então utilizado pelos mercadores das cidades italianas para o registro das transações comerciais. Os primeiros livros de contabilidade datam do final do século XIII ao início do século XIV. Pacioli escreveu sua obra logo após a invenção da imprensa, em italiano e usando os números hindus-arábicos. Com uma tiragem de dois mil exemplares, a Summa tinha 615 páginas e tornou-se a obra matemática mais lida na Itália, durante anos (GLEESON-WHITE, 2012). 
Diversas obras de contabilidade publicadas em outras línguas nos anos seguintes estavam baseadas na Summa. Gleenson-White (2012) afirma que o livro foi traduzido para diversas línguas, como o inglês, alemão, francês e russo. Na Holanda, o principal divulgador da obra de Pacioli foi Simon Stevin (1548-1620), cientista e comerciante. Stevin escreveu um livro sobre o uso da contabilidade na área pública. Mais importante, Stevin era amigo do Princípe Maurício de Nassau, que introduziu o método na gestão dos territórios holandeses (GLEESON-WHITE, 2012). Talvez, por este motivo, seja possível afirmar que coube aos holandeses a primazia de adotar o método no Brasil durante a invasão holandesa (SILVA, 2013).

A primeira tradução do livro de Pacioli para a língua portuguesa foi de Nicolas Gaspar, com o Tratado da prática de Arismética, publicado originalmente em 1519. Esta obra teve outras dez edições, de 1530 a 1716, e baseava-se na Summa de Pacioli. Entretanto, Gaspar não ensinava as partidas dobradas nesta obra. Ou seja, foi uma tradução incompleta da obra de Pacioli.

Somente com o livro 'Mercado Exacto nos seus livros de contas ou Methodo Facil para qualquer mercador, e outros arrumarem as fuas contas com a clareza neceffaria, com feu Diario, pelos princípios das Partidas dobradas, fegundo a determinação de Sua Mageftade', de João Baptista Bonavie é que o método aparece em língua portuguesa, em 1758. O aparecimento desta obra está associado à criação das escolas de comércio pelo Marquês de Pombal.

Um grande passo se deu no sentido de normatizar as práticas contábeis no Brasil quando da chegada da família Real ao Brasil. D. João VI, em 1808, obriga os Contadores Gerais da Real Fazenda a aplicarem o método das partidas dobradas na escrituração mercantil (SCHMIDT, 2000). Com a família real, chegam também obras de contabilidade e profissionais com conhecimento de partidas dobradas. Entretanto, a contabilidade das entidades era de baixa qualidade, a exemplo da crítica do jornal A Malagueta (CARTA sobre as couzas do Thesouro, 2013), que comparava a contabilidade do Banco do Brasil a uma escrituração de um mascate da Lapa.

A normatização contábil avançou com a Lei de 4 de outubro de 1831, onde se tentava organizar o tesouro. Com 118 artigos, esta lei obrigava a adoção do método das partidas dobradas, muito embora na prática este método na contabilidade pública só foi adotado no início do século XX.

Em 1850, é aprovado o Código Comercial tendo por base as legislações de países europeus. Este código foi aprovado após longo debate no legislativo. Antes, um relatório do Ministério do Império (BRASIL, 1836) já comentava a necessidade de uma norma para disciplinar as entidades comerciais. O Código Comercial trazia artigos sobre constituição de sociedades, com ênfase na atividade comercial marítima. O Código Comercial, em 1850, foi um importante instrumento que contribuiu para a contabilidade brasileira e uma das primeiras manifestações de legislação relacionada a esse assunto no país. Foi a partir dele que se obrigou a escrituração contábil e a elaboração da demonstração do Balanço Geral para empresas comerciais (SCHMIDT, 2000). Entretanto, o código inibia a evidenciação contábil, que só era obrigada com ordem judicial para casos específicos.

Juntamente com a aprovação do código, diversas outras legislações foram aprovadas durante o segundo império. O Decreto 2433, de 1859, trata dos problemas de herança e o registro contábil. Em 1860, é promulgada a Lei 1083, considerada a primeira lei das sociedades por ações. Com oito artigos e uma grande preocupação com o sistema financeiro, a norma obrigava que a entidade tivesse autorização do governo para seu funcionamento. A Lei

GєECont, v.2, n. 2, Floriano-PI, Jul-Dez. 2015. 
1083 trouxe uma série de normatizações complementares, aprovadas meses depois, particularmente aquelas voltadas para o sistema financeiro.

Somente com o Decreto 2679/1860, o Brasil teve uma norma mais detalhada sobre contabilidade. Esta norma obrigava os bancos a publicar balanços mensais, com relatório de administração e comissão de exame de contas. Para as sociedades anônimas, a periodicidade era semestral.

As regras instituídas durante o segundo reinado perduraram durante muitas décadas e serviam de base para a contabilidade. Em 1891, no governo do general Deodoro, tem-se o decreto 434. Com 231 artigos, esta norma trata das sociedades anônimas, incluindo sua constituição, administração, dissolução, assembleia geral, entre outros assuntos. Entretanto, a parte contábil desta norma é praticamente inexistente, o que justifica o fato de ser raramente lembrada na história contábil.

Em 1892, adota-se a cobrança de imposto sobre os dividendos recebidos. Em 1921, tributam-se os lucros das profissões liberais. A Lei 4625, de 1922, avança ao usar as informações contábeis para fins fiscais. A lei continha detalhamento sobre a cobrança do imposto sobre a renda; para isto, era necessário detalhar a apuração do lucro líquido das entidades. Como o Código Comercial de 1850 proibia que o fisco examinasse os livros contábeis da empresa, a apuração do imposto de renda era feita a partir da declaração da própria entidade, sem nenhum tipo de fiscalização.

Em 1940, o governo Vargas promulga o Decreto-Lei 2627, que estabeleceu sobre a elaboração de demonstrações contábeis e aspectos diversos sobre a constituição, liquidação e fusão de entidades (COELHO; LINS, 2010). Por este normativo, a Contabilidade também passa a ter vinculação com a legislação societária, pois passam a existir regras para avaliação de ativos e para apuração e distribuição de lucros.

O Decreto-Lei 2627 tinha 180 artigos, com um capítulo específico sobre a contabilidade, ao contrário do Decreto 434. A norma previa a depreciação, com a criação de fundos de amortização, os critérios de mensuração patrimonial, incluindo a possibilidade de usar o preço corrente, a existência da provisão para crédito de liquidação duvidosa, a consideração de despesas de instalação como ativo e a constituição de um fundo de reserva do lucro líquido apurado. Além disto, apresentava a divisão do ativo (imobilizado, disponível, realizável em curto prazo e a longo prazo, resultado pendente e conta de compensação) e passivo (exigível e não exigível, sendo este dividido em capital, reservas legais e estatutárias, resultado pendente e contas de compensação). A norma também detalhava o que deveria constar da conta de lucros e perdas.

Um aspecto interessante do Decreto-Lei diz respeito à materialidade. A norma proibia a denominação de "diversas contas" ou semelhantes que correspondesse a $10 \%$ do capital social.

\subsection{Da Escola Europeia à Influência Anglo-Saxônica}

Desde o início, na evolução contábil do Brasil, fica claro que a legislação sempre interferiu na contabilidade nacional. Alguns autores consideram que isto decorre da inoperância das associações de classe (IUDÍCIDUS, 1994, apud SCHMIDT, 2000). Niyama e Silva (2010, p. 86) afirmam de forma parecida que: "nesse ambiente legal e institucional, pode-se observar que é politicamente fraca a atuação dos órgãos representativos de classe ou institutos voltados à profissão contábil".

Até o início do século XX, a Escola Italiana influenciou fortemente a Contabilidade brasileira, com o Método das Partidas Dobradas, proposto por Lucca Pacioli, e com a 
inspiração européia dada a legislação comercial. Essa escola teve adeptos no Brasil de grande importância para a ciência no país: Carlos de Carvalho, Francisco D'Auria e Frederico Herrmann Júnior, que adotaram o patrimonialismo como corrente de pensamento, (SCHMIDT, 2000).

O Brasil entra na década de 1950 recebendo forte influência dos Estados Unidos. Nos governos de Getúlio Vargas e Juscelino Kubitschek, foram fomentados o aumento da industrialização e a abertura ao capital externo para investimento. Com a vinda das indústrias norte-americanas ao Brasil, a influência da Escola Norte-Americana se espalhou (LOPES DE SÁ, 1997).

A partir da década de 1950, a Contabilidade em todo o mundo, não só no Brasil, passa por mudanças e necessita cada vez mais que se criem normas para atender a uma nova realidade. Lopes de Sá (1997) divide a história da Contabilidade em vários períodos e o que corresponde da década de 1950 até hoje é o chamado Período Filosófico-Normativo. Esse período é marcado pela preocupação de se normalizar essa ciência e um dos fatores que gerou isso foi a "globalização dos mercados e a necessidade de harmonizações normativas". Esse fator se refere à abertura para circulação de capitais, a pressão exercida pelas nações mais desenvolvidas para colocação de seus produtos no mercado mundial e, principalmente, à intervenção de empresas de Contabilidade anglo-saxônicas (LOPES DE SÁ, 1997).

Iudícibus (2000) aponta para um dos motivos marcantes da mudança de influência da Escola Italiana para a Escola Norte-Americana, a introdução de um novo método de ensino da Contabilidade, pelo professor José Costa Boucinhas. Ele adotou o método didático norteamericano, baseado no livro Introductory Accounting de Finney e Miller.

A fundação, na Faculdade de Ciências Econômicas e Administrativas da USP, de cursos de treinamento em Contabilidade e Finanças oferecidos por grandes empresas e firmas de auditoria anglo-saxônicas exerceram forte influência para a mudança de visão. A entrada dessas firmas de auditoria influenciou o entendimento das normas e dos procedimentos de Contabilidade. Dessa forma, Iudícibus (2000) justifica muitas das normas aplicadas ao Brasil, lembrando que as grandes empresas de auditoria trabalhavam para quase todas as grandes subsidiárias de multinacionais. Assim, exerciam influência sobre os procedimentos adotados e isto pode ter influenciado os legisladores. Além disto, alguns dos profissionais destas empresas participaram do processo de regulação contábil.

Iudícibus (2000, p. 37) dá exemplos na própria legislação brasileira da nítida mudança de influência europeia para a norte-americana ao afirmar que "a legislação comercial, que até a antiga Lei da Sociedade por Ações, era de inspiração europeia (com traços marcantes brasileiros na classificação dos balanços das S.A.), passa a adotar uma filosofia nitidamente norte-americana, a partir, principalmente, da Resolução $n^{\circ} 220$ e da Circular $n^{\circ} 179$ do Banco Central". Até então a Contabilidade seguia influência europeia, ou seja, uma Contabilidade legalista, que não tinha como principal objetivo as demonstrações contábeis para atendimento das necessidades dos usuários da informação (NIYAMA; SILVA, 2010).

A Lei $n^{\circ}$ 6.404/76 segue essa tendência norte-americana e se faz necessária para fortalecer o mercado de capitais de risco e para sobrevivência da empresa privada (SCHMIDT, 2000), por meio da produção de demonstrações contábeis confiáveis. Pode-se perceber que a Contabilidade passa a ter uma preocupação com as informações contábeis destinadas aos usuários dessas informações que não se tinha até meados de 1970 (NIYAMA; SILVA, 2011). Os acionistas - um dos principais usuários da informação - passam a ter um papel importante, por um motivo que explica Schimdt (2000, p. 213): 
A mobilização da poupança popular e seu encaminhamento voluntário para o setor empresarial exigem, contudo, o estabelecimento de uma sistemática que assegure ao acionista minoritário o respeito a regras definidas e equitativas, às quais, sem imobilizar o empresário em suas atividades, ofereçam atrativos suficientes de segurança e rentabilidade.

Considerando a forte influência dos Estados Unidos, a inserção de grandes empresas e a abertura para mercados de capitais, foi necessária a elaboração de uma lei que regulamentasse essa fase da Contabilidade no Brasil. Isso se concretizou na Lei $\mathrm{n}^{\circ}$ 6.404, de 15 de Dezembro de 1976. Silva (1960, p. 28 apud SCHMIDT, 2000, p. 2013) coloca essa lei como uma forma de incorporar definitivamente as tendências da Escola Americana:

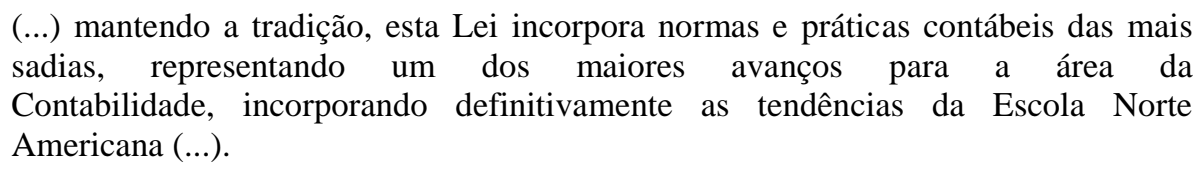

Iudícibus, Martins e Gelbcke (1978, p. 35) afirmam que essa lei não veio apenas para fortalecer o mercado de capitais, mas, também, o meio empresarial do país: "A nova Lei da S.A. (Lei $n^{\circ}$ 6.404, de 15-12-76) apresentou profundas inovações no que se refere às demonstrações financeiras e ao seu conteúdo, bem como aos princípios contábeis estabelecidos".

O objetivo essencial que se pode notar relativamente às demonstrações financeiras e aos princípios contábeis é o da ampliação da quantidade de informações que as sociedades terão de divulgar, bem como da melhoria da qualidade e confiabilidade das referidas informações.

Segundo Iudícibus (2000), as principais contribuições da lei, sob o aspecto contábil, são as seguintes: clara separação entre Contabilidade Comercial (Contabilidade "Contábil") e Contabilidade para fins fiscais; aperfeiçoamento da classificação das contas do balanço; introdução da reavaliação a valor de mercado; introdução do método de equivalência patrimonial na avaliação de investimentos; criação da reserva de lucros a realizar; e aperfeiçoamento do mecanismo de correção monetária.

\subsection{Contexto Econômico: Mercado de Capitais}

A Lei ${ }^{\circ}$ 6.404/76 surgiu com o intuito de modernizar o mercado de capitais e retirá-lo de uma estagnação que já existia desde a década de 60.

No fim da década de 50 e início da década de 60, havia insegurança em investir no mercado de capitais devido à alta inflação e à limitação à taxa de juros que foi estabelecida pela Lei de Usura (Portal do Investidor, s.d.).

Para regulamentar o mercado de capitais no Brasil, em 1965, houve a Lei no 4.728 , que também criou a figura do auditor independente, que só apareceu em 1972, pela Resolução $\mathrm{n}^{\circ}$ 220 do Banco do Brasil. Mas ainda não conseguiu impulsionar o desenvolvimento do mercado de capitais, como o governo esperava.

O Governo Federal incentivou o mercado de ações, com diversas políticas públicas. De início essa medida aumentou a demanda por ações, porém não houve um aumento na mesma proporção de emissão de ações, o que gerou uma tendência de especulação, que foi chamado o "boom" da bolsa do Rio de Janeiro. Isso provocou grandes prejuízos aos acionistas e causou mais desconfiança ao mercado acionário (Portal do Investidor, s.d.).

Buscando uma recuperação da credibilidade desse mercado, houve a criação de vários mecanismos, um deles foi a Lei $\mathrm{n}^{\circ}$ 6.404/76, Lei das Sociedades Anônimas, que visava modernizar as regras que regiam as sociedades anônimas (SCHMIDT, 2000, p. 213): "Essa lei GєECont, v.2, n. 2, Floriano-PI, Jul-Dez. 2015. 
procurou criar a estrutura jurídica necessária ao fortalecimento do mercado de capitais de risco no País, imprescindível à sobrevivência da empresa privada na fase atual da economia brasileira".

Além de recuperar o mercado, uma nova lei tratando das Sociedades Anônimas se fazia necessária pela nova estrutura econômica do país. A antiga Lei das Sociedades Anônimas, Decreto-Lei 2.627 de 1940, foi idealizada pelo jurista Trajano de Miranda Valverde, no governo de Getúlio Vargas, com o intuito de atender empresas que, normalmente, eram fechadas a familiares. Com a abertura de mercado do Brasil, a necessidade de se produzir informações de qualidade e confiáveis que demonstrassem a realidade do patrimônio da entidade para fornecedores e clientes externos, instituições financeiras, novos investidores, dentre outros novos usuários, esta legislação não se fazia mais suficiente.

\subsection{Avanço da Contabilidade no Brasil com a Lei $N^{0}$ 6.404/76}

A Lei $n^{0}$ 6.404/76 marcou uma nova fase da Contabilidade brasileira, pois institucionalizou as normas contábeis, provocando inovações na forma de elaborar demonstrações e no seu conteúdo e nos princípios contábeis (IUDÍCIBUS; MARTINS; GELBCKE, 1978, p. 35). Essa lei aumentou o número de informações obrigatórias que as sociedades deveriam publicar e a regulamentação dos princípios geralmente aceitos, com isso buscava mais qualidade e confiabilidade e uma representação real das informações contábeis destinadas aos usuários da informação, tanto internos quanto externos.

O quadro 1 mostra uma visão geral e resumida das mudanças mais significativas que a Lei $\mathrm{n}^{\mathrm{o}} 6.404 / 76$ causou à contabilidade brasileira e que permitiu aos profissionais da área terem regulamentadas as normas que refletiam a influência norte-americana e que agora visavam mais as informações para serem utilizadas por seus usuários. A seguir, serão apresentadas as principais mudanças que a lei trouxe, em relação a normas anteriores, para que atingisse esse objetivo, sumarizadas no quadro 1. 
Quadro 1 - Principais alterações na Lei.

\begin{tabular}{|c|c|c|}
\hline $\begin{array}{|ll|}\text { ITENS QUE } & \text { TIVERAM } \\
\text { MUDANÇAS } & \\
\end{array}$ & $\begin{array}{l}\text { COMO ERA ANTES DA } \\
\text { LEI 6.404/76? }\end{array}$ & O QUE MUDOU COM A LEI 6.404/76? \\
\hline Demons trações Financeiras & $\begin{array}{l}\text { Balanço Geral e Demonstração } \\
\text { de Lucros e Perdas }\end{array}$ & $\begin{array}{l}\text { Balanço Patrimonial, Demonstração dos Lucros ou } \\
\text { Prejuízos Acumulados, Demonstração do Resultado do } \\
\text { Exercício, Demonstração das Origens e Aplicações de } \\
\text { Recursos e Notas explicativas. Demonstrações } \\
\text { consolidadas e comparativas. }\end{array}$ \\
\hline $\begin{array}{l}\text { Classificação quanto às } \\
\text { contas do Balanço } \\
\text { Patrimonial }\end{array}$ & $\begin{array}{l}\text { Ativo: apresentados na forma } \\
\text { decrescente de valor. Passivo: } \\
\text { iniciava pelas dívidas de longo } \\
\text { prazo (ideia de estabilidade) }\end{array}$ & $\begin{array}{l}\text { Ativo: contas são dispostas conforme a ordem } \\
\text { decrescente de liquidez. Passivo: contas são dispostas } \\
\text { pela ordem decrescente de exigibilidade. Patrimônio } \\
\text { Líquido: representa a diferença entre passivo e ativo. }\end{array}$ \\
\hline Corre ção Mone tária & $\begin{array}{l}\text { Obrigatória para o imobilizado e } \\
\text { o capital }\end{array}$ & Correção do permanente e do patrimônio líquido. \\
\hline Escrituração & $\begin{array}{l}\text { Vinculação da contabilidade } \\
\text { com a legislação fiscal }\end{array}$ & $\begin{array}{l}\text { Separação de Contabilidade Comercial (ou a } \\
\text { Contabilidade “contábil") da Fiscal: a escrituração } \\
\text { deverá ser feita de acordo com a nova lei e os } \\
\text { princípios de contabilidade geralmente aceitos } \\
\end{array}$ \\
\hline $\begin{array}{l}\text { Critérios de avaliação dos } \\
\text { ativos e de registro do } \\
\text { passivo }\end{array}$ & $\begin{array}{l}\text { A provisão para devedores } \\
\text { duvidosos eram baseadas na } \\
\text { legislação fiscal, ou seja, existia } \\
\text { uma porcentagem fixa a ser } \\
\text { descontada. Existência de } \\
\text { depreciação acelerada. }\end{array}$ & $\begin{array}{l}\text { A provisão para devedores duvidosos contabilizada } \\
\text { pelo valor necessário e suficiente para cobrir as perdas } \\
\text { prováveis. As depreciações buscam refletir o desgaste } \\
\text { ou obsoletismo do imobilizado. Reavaliação tem como } \\
\text { objetivo aproximar as demonstrações da realidade. } \\
\text { Equivalência patrimonial permite que as companhias } \\
\text { reconheçam os resultados de seus investimentos no } \\
\text { momento em que tais resultados são gerados. }\end{array}$ \\
\hline $\begin{array}{l}\text { Reservas de Lucros a } \\
\text { Realizar }\end{array}$ & & $\begin{array}{l}\text { A finalidade é evidenciar os lucros ainda não realizados } \\
\text { financeiramente pela companhia e não distribuir } \\
\text { dividendos obrigatórios. }\end{array}$ \\
\hline
\end{tabular}

Fonte: Elaboração própria.

\subsubsection{Demonstrações Financeiras}

Uma das mudanças significativas com a nova Lei das S/A foi a introdução de novas demonstrações que se tornaram obrigatórias para publicação. A Lei no 2.627/1940 obrigava a publicação do Balanço Geral e da Demonstração de Lucros e Perdas. Com a lei de 1976, passaram a ser exigidos Balanço Patrimonial, Demonstração dos Lucros ou Prejuízos Acumulados, Demonstração do Resultado do Exercício, Demonstração das Origens e Aplicações de Recursos e Notas explicativas às demonstrações financeiras.

A Circular no 179, de 1972, do Banco Central do Brasil já exigia o Balanço e a Demonstração de Resultados, mas esta última não mostrava de forma clara o lucro líquido do período, por isso se separou, nessa norma de dezembro de 1976, Demonstração do Resultado do Exercício e Demonstração dos Lucros e Prejuízos Acumulados. Passa a ter, então, uma representação do que acontece para a formação do lucro e prejuízo líquido do exercício, o que são contas de resultado, e o que acontece com a conta de Lucros Acumulados que configura no Balanço Patrimonial.

A Demonstração de Origens e Aplicações de Recursos, que se tornou obrigatória a partir de 1976 e vigorou até 2007, se entendia que essa demonstração permitia avaliar a 
eficiência e o esforço empresarial desenvolvidos no exercício do período. Mostrava, separadamente, os recursos gerados pela empresa e a forma como eram aplicados.

O conteúdo da Demonstração do Resultado do Exercício, a partir dessa lei, permitiu mostrar de forma mais clara o lucro ou prejuízo líquido do exercício e com detalhes as contas de receitas, custos e despesas. Foi nessa lei que surgiu o conceito de lucro líquido, e estabeleceu critérios de classificação de certas despesas que, conforme mencionado por Iudícibus, Martins e Gelbcke (1978), eram indevidamente classificadas como apropriação de lucros.

O Imposto de Renda, por exemplo, teve sua classificação alterada. Anteriormente, era classificado como apropriação de lucros e passa a receber o tratamento de despesa, ou seja, diminuindo o resultado do exercício, fazendo assim o uso da competência. Assim como aconteceu com as participações e contribuições que passaram a ser tratadas como despesa. A nova lei também propôs que o efeito da inflação fosse levado a resultado, independentemente se for positivo ou negativo, ou seja, o tratamento contábil como receita ou despesa.

As notas explicativas, também já exigidas pela Circular $n^{\circ} 179$, passaram a ser de uso geral por todas as Sociedades Anônimas. O objetivo delas também é aumentar a clareza das atividades operacionais da empresa, dos princípios adotados, dos ajustes feitos e por eventos subsequentes ao encerramento do exercício, ajudando, assim, na tomada de decisões pelos usuários internos e externos da informação.

Passou a ser necessário também que as demonstrações financeiras do exercício atual sejam publicadas juntamente com os saldos do exercício anterior para que se pudesse comparar as informações (IUDÍCIBUS; MARTINS; GELBCKE, 1978). Essa mudança permitiu que os usuários - tais como acionistas, credores e administradores - tivessem, de forma evidente, informações de exercícios passados em relação ao atual, permitindo traçar perspectivas quanto à empresa.

\subsubsection{Classificação das Contas no Balanço}

Ainda com respeito às demonstrações contábeis, a lei 6.404/76 estabelece o modelo de como as contas devem ser classificadas e posicionadas no Balanço Patrimonial, buscando maior clareza e aproximação com a realidade da situação patrimonial da empresa, diferente do que se tinha antes. No Decreto-Lei $\mathrm{n}^{\circ} 2.627 / 47$, os ativos eram apresentados na forma decrescente de valor, ou seja, buscava-se colocar os bens de maior valor primeiramente, por isso o grupo do imobilizado (máquinas e equipamentos) geralmente eram os primeiros a serem apresentados. No passivo, buscava-se a ideia de a empresa se manter estável por muito tempo, consequentemente, ele iniciava pelas dívidas de longo prazo. Com a Lei Societária (6.404/76), no ativo as contas são dispostas conforme a ordem decrescente de liquidez e no passivo pela ordem de decrescente de prioridade de pagamento, ou seja, cuja exigibilidade ocorre antes, há, ainda, a separação do patrimônio líquido que representa a diferença entre passivo e ativo - valor líquido da empresa (IUDÍCIBUS; MARTINS; GELBCKE, 2010, p. 2). 
Quadro 2 - Estrutura do Balanço Patrimonial.

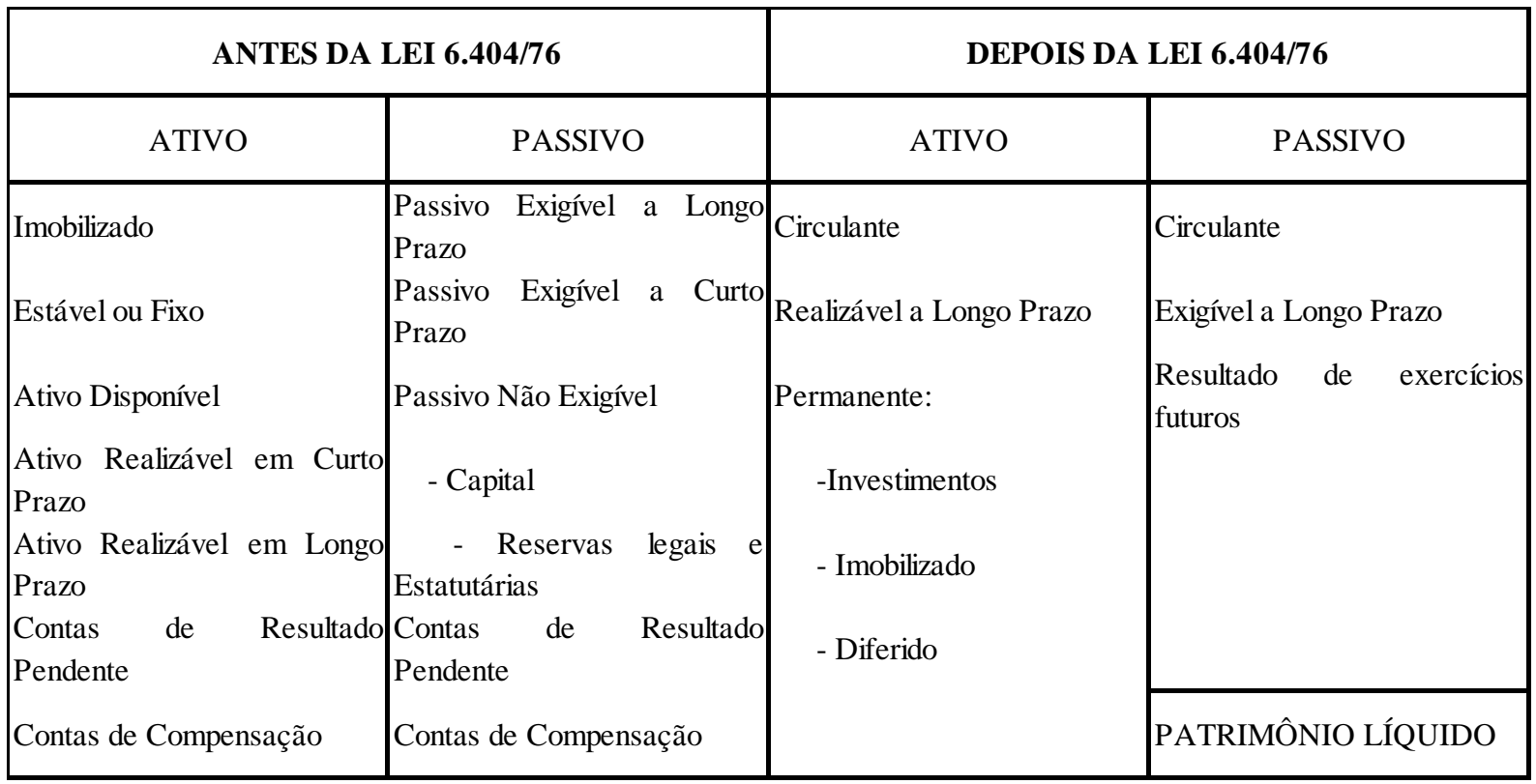

Fonte: Adaptado de Coelho; Lins (2010, p. 176-177).

Como se percebe com a apresentação do quadro 2 , há a criação do ativo circulante que aborda o disponível e o realizável a curto prazo; é eliminado o grupo ativo pendente, sendo contabilizadas as contas pagas antecipadamente em conta no ativo circulante ou no ativo diferido ou até mesmo eliminadas; retira o grupo imobilizado com os subgrupos imobilizado técnico e imobilizado financeiro e passa a existir o grupo ativo permanente que engloba os mesmos subgrupos e o ativo diferido; eliminou a obrigatoriedade das contas de compensação; as contas redutoras de ativo como depreciação acumulada, provisão para crédito de liquidação duvidosa, dentre outras, deixam de ser classificadas como ativo não exigível e passam a reduzir suas contas correspondentes; o ativo realizável a longo prazo passa a compreender um exercício social (normalmente um ano), não mais 180 dias (IUDÍCIBUS; MARTINS; GELBCKE, 1978).

O passivo passa a ser registrado pelo regime de competência e a definição entre circulante e exigível a longo prazo também passa a compreender um exercício social; o passivo pendente é substituído pelo grupo resultados de exercícios futuros que corresponde às receitas diferidas; adota-se o patrimônio líquido ao invés do grupo não exigível para as contas de capital, reservas (capital ou lucros) e lucros e prejuízos acumulados (IUDÍCIBUS; MARTINS; GELBCKE, 1978, p. 43).

Essas mudanças, retirando algumas contas e agrupando outras, se fez necessário pelo que explica o artigo 178 da referida lei: "Art. 178. No balanço, as contas serão classificadas segundo os elementos do patrimônio que registrem, e agrupadas de modo a facilitar o conhecimento e a análise da situação financeira da companhia".

Iudicíbus et al. (2010, p. 2) colocam a importância da classificação das contas no balanço: "Portanto, é importante que as contas sejam classificadas no balanço de forma ordenada e uniforme, para permitir aos usuários uma adequada análise e interpretação da situação patrimonial e financeira". 


\subsubsection{Correção Monetária}

Em 1964, a Lei $\mathrm{n}^{\circ} 4.357$ tornou obrigatória para o ativo imobilizado e para o capital de pessoas jurídicas a correção monetária, com o objetivo de resolver as distorções causadas pela inflação. Essa lei sofreu muitas críticas, entretanto, foi o que resolveu, até aquele momento, as distorções que existiam nos relatórios contábeis. Já a Lei $\mathrm{n}^{\circ}$ 6.404/76 permitiu um aperfeiçoamento do mecanismo de correção monetária, segundo Iudicíbus, Martins, Gelbcke e Santos (2010, p. 10):

Originalmente, a Lei $\mathrm{n}^{\mathrm{o}} 6.404 / 76$ previa a obrigatoriedade do reconhecimento dos efeitos da inflação nas demonstrações contábeis, por sistemática simples e eficiente, através da chamada Correção Monetária do Balanço, que resultava na apuração do ativo permanente, patrimônio líquido e lucro mais corretos.

Portanto, passam a ter correção os investimentos, o ativo diferido e as contas do patrimônio líquido e a correção monetária para ativo imobilizado passa a ser feita no próprio balanço, não mais no exercício seguinte, dessa forma evita a distorções das informações apresentadas.

\subsubsection{Escrituração}

A vinculação da contabilidade com a legislação fiscal - prática histórica na Contabilidade do Brasil - limitava a correta adoção prática ou evolução dos princípios contábeis geralmente aceitos e provocava distorções nos resultados (IUDÍCIBUS; MARTINS; GELBCKE, 1978). Um exemplo disso foi o Decreto $\mathrm{n}^{\circ} 61.083 / 67$ que autorizava, em alguns casos, a utilização da depreciação acelerada, o que causou várias distorções, pela falta de distinção entre Contabilidade para fins financeiros e para fins fiscais, como a alteração do resultado e a redução do valor do imobilizado (SCHMIDT, 2000). No segundo parágrafo do artigo 177 da Lei das S/A, que trata da escrituração, há a separação de Contabilidade Comercial (ou a Contabilidade "contábil") da Contabilidade Fiscal, obrigando que a escrituração deverá ser feita de acordo com a nova lei e os princípios de contabilidade geralmente aceitos.

Art. 177. A escrituração da companhia será mantida em registros permanentes, com obediência aos preceitos da legislação comercial e desta Lei e aos princípios de contabilidade geralmente aceitos, devendo observar métodos ou critérios contábeis uniformes no tempo e registrar as mutações patrimoniais segundo o regime de competência.

$\S 2^{\circ}$. A companhia observará em registros auxiliares, sem modificação da escrituração mercantil e das demonstrações reguladas nesta Lei, as disposições da lei tributária, ou de legislação especial sobre a atividade que constitui seu objeto, que prescrevam métodos ou critérios contábeis diferentes ou determinem a elaboração de outras demonstrações financeiras.

Isto foi um importante avanço já que, até meados dos anos 70, a contabilidade tinha forte vinculação com a escrituração e o atendimento de exigências fiscais (NIYAMA; SILVA, 2011).

\subsubsection{Critérios de Avaliação dos Ativos e de Registro dos Passivos}

A mudança nos critérios de avaliação buscou, principalmente, mostrar as informações de forma fidedigna, tentando aproximar o valor do patrimônio contabilizado da realidade, afastando, assim da forma fixa que se tem quando os valores são encontrados por meio da legislação fiscal. 
A provisão para devedores duvidosos deixa de ter como base a legislação fiscal necessária para fins de imposto de renda -, passa a ser contabilizada pelo valor necessário e suficiente para cobrir as perdas que, provavelmente, se terá nas contas a receber.

A depreciação acelerada passa a ser considerada apenas para fins fiscais, não sendo mais contabilizada. Dessa forma, a depreciação busca refletir o desgaste ou obsoletismo do imobilizado.

As duas importantes mudanças nos critérios de avaliação: a reavaliação a valor de mercado e o método de equivalência patrimonial são tratadas de forma mais detalhada, a seguir.

\subsubsection{Reavaliação a Valor de Mercado}

Na Lei $n^{\circ}$ 6.404/76, temos a seguinte disposição para a avaliação a valor de mercado:

Art. 183. No balanço, os elementos do ativo serão avaliados segundo os seguintes critérios:

I - os direitos e títulos de crédito, e quaisquer valores mobiliários não classificados como investimentos, pelo custo de aquisição ou pelo valor do mercado, se este for menor; serão excluídos os já prescritos e feitas as provisões adequadas para ajustá-lo ao valor provável de realização, e será admitido o aumento do custo de aquisição, até o limite do valor do mercado, para registro de correção monetária, variação cambial ou juros acrescidos;

$\S 1^{\circ}$. Para efeitos do disposto neste artigo, considera-se valor de mercado:

a) das matérias-primas e dos bens em almoxarifado, o preço pelo qual possam ser repostos, mediante compra no mercado;

b) dos bens ou direitos destinados à venda, o preço líquido de realização mediante venda no mercado, deduzidos os impostos e demais despesas necessárias para a venda, e a margem de lucro;

c) dos investimentos, o valor líquido pelo qual possam ser alienados a terceiros.

A reavaliação foi criada com o objetivo principal de atender a necessidade de se contabilizar de forma mais adequada o imobilizado, pois é um ativo que tende a ter grande importância na empresa e tende a ter grandes defasagens entre valores de custo e de mercado. Mas pode ser aplicada, excepcionalmente, para os outros elementos do ativo (como estoques, diferimentos, investimentos), principalmente, os que são destinados à comercialização (IUDÍCIBUS; MARTINS; GELBCKE, 1978).

Essa técnica permite que os produtos que serão vendidos pela empresa sejam melhor custeados e representem de maneira mais próxima os custos de reposição.

No Brasil, essa técnica leva um tratamento mais conservador. É utilizada na contabilidade com o objetivo de aproximar as demonstrações da realidade. É necessária quando se percebe que os ativos registrados apresentam um valor menor no mercado do que o valor pelo qual foram registrados. Assim, não se passa a impressão de que o patrimônio da empresa é maior do que realmente é.

\subsubsection{Método de Equivalência Patrimonial na Avaliação de Investimentos}

Antes da Lei 6.404, os investimentos eram avaliados pelo método de custo mais ações bonificadas ou pelo valor patrimonial, dos dois o menor. Como afirma Iudícibus, Martins e Gelbcke (1978, p. 171): 
Esse método baseava-se no fato de que a empresa investidora registrava somente as operações ou transações baseadas em atos formais, como por exemplo, os dividendos que eram registrados como receita no momento em que fossem declarados e distribuídos pela empresa coligada ou controlada e as ações bonificadas que eram registradas como aumento dos investimentos no momento em que a coligada efetuava aumento de capital, através de Assembleia dos acionistas.

Esse método foi estabelecido pela Circular $n^{\circ} 179$ do Banco Central do Brasil a ser seguido por empresas de capital aberto, sendo permitido o mesmo procedimento por outras empresas. Após a publicação da Lei Societária, ficou decretado que os resultados e quaisquer variações patrimoniais de uma controlada ou coligada devem ser contabilizados no momento em que são gerados, independentemente se serão ou não distribuídos.

Essa diferença de tratamento pode afetar o resultado de uma empresa, gerando, consequentemente, valor patrimonial diferente das ações e dos lucros e das reservas disponíveis para distribuição. Logo, a importância do novo tratamento da equivalência patrimonial foi a nova maneira de registrar para eliminar muitas distorções como, por exemplo, no mercado de capitais, em que as companhias reconhecem os resultados de seus investimentos no momento em que tais resultados são gerados naquelas empresas, e não somente no momento em que são distribuídos na forma de dividendos ou de ações bonificadas.

\subsubsection{Criação da reserva de lucros a realizar}

A principal característica dessa reserva é que ela é optativa, ou seja, se a empresa apurar lucros já contabilizados e integrantes do lucro líquido do exercício, e que não foram financeiramente realizados, a administração poderá decidir por constituir essa reserva. Sua contabilização será no balanço, debitando na conta Lucros Acumulados e creditando em Reserva de Lucros a realizar, conforme art. 197 da Lei 6.404/76:
Art. 197. No exercício em que os lucros a realizar ultrapassarem o total deduzido nos termos dos artigos 193 a 196, a assembleia-geral poderá, por proposta dos órgãos da administração, destinar o excesso à constituição de reserva de lucros a realizar.
Parágrafo único. Para os efeitos deste artigo, são lucros a realizar:
a) o saldo credor da conta de registro das contrapartidas dos ajustes de correção monetária (artigo 185, $\S 3^{\circ}$ );
b) o aumento do valor do investimento em coligadas e controladas (artigo 248, III);
c) o lucro em vendas a prazo realizável após o término do exercício seguinte.

A finalidade dessa conta é evidenciar uma parcela de lucros ainda não realizados financeiramente pela companhia e também não distribuir dividendos obrigatórios, fixado como porcentagem de lucro do exercício, sobre essa mesma parte (IUDÍCIBUS; MARTINS; GELBCKE, 1978, p. 343).

\section{CONSIDERAÇÕES FINAIS}

A Lei $n^{\circ}$ 6.404/76 foi criada num período em que era necessário que a Contabilidade regulamentasse uma posição a ser seguida, já que o Brasil antes tinha como base muito da Contabilidade europeia e já tinha incorporado em algumas normas e instituições de ensino de grande peso a influência norte-americana. Fazia-se indispensável, então, alguma norma que orientasse os profissionais da área sobre o que deveria ser feito diante da Contabilidade que se mostrava dividida. 
Além disso, a lei teve como impulso a estagnação do mercado de capitais que precisava crescer, para isso era necessário que as empresas transmitissem confiança e clareza nas informações que eram passadas, principalmente, aos usuários externos, tais como possíveis investidores e governo.

Diante dessa situação em que o Brasil se encontrava a lei buscou tornar obrigatórios meios que acabaram por refletir a influência norte-americana e que transmitissem essa segurança, com o objetivo de obter uma resposta positiva no mercado de capitais. Dessa forma, se criou ou regulamentou normas que significaram avanços para a contabilidade brasileira - abordadas neste trabalho -, a citar: o aumento de volume de demonstrações contábeis, que possibilitam ter mais informações de forma detalhada da situação patrimonial da empresa; a classificação das contas do Balanço Patrimonial, permitindo uma análise adequada interpretação da situação patrimonial e financeira; a correção monetária para mais itens do Balanço Patrimonial, o que resultava numa apuração mais correta do ativo permanente, patrimônio líquido e lucro; a vinculação da escrituração com os princípios geralmente aceitos e com a Lei Societária, numa tentativa de separar, assim, a Contabilidade da legislação fiscal; estabelecimento de critérios de avaliação de ativo e de registro de ativos, buscando retratar a realidade do valor patrimonial da empresa; criação da conta Reserva de Lucros a Realizar que tem por objetivo evidenciar a parcela do lucro não realizado para que não seja distribuído um valor que a empresa ainda não possui.

\section{REFERÊNCIAS}

BRASIL. Ministério do Império. Relatório da Repartição dos Negócios do Império. Ano de 1835 apresentado a Assembleia Geral Legislativa na sessão ordinária de 1836. Rio de Janeiro: Typographia Nacional, 1836.

BRASIL. Lei 6.404, de 15 de dezembro de 1976. Dispõe sobre as sociedades por ações. Disponível em: <http://www2.camara.leg.br/legin/fed/lei/1970-1979/lei-6.404-15dezembro-1976-368447-publicacaooriginal-1-pl.html>. Acesso em 19 abr. 2013.

CARTA sobre as couzas do Thesouro. A Malagueta, Rio de Janeiro, 27 abr. 1822. Disponível em: < http://hemerotecadigital.bn.br/>. Acesso em 18 mar 2013.

COELHO, Cláudio Ulysses Ferreira; LINS, Luiz dos Santos. Teoria da Contabilidade: abordagem contextual, histórica e gerencial. São Paulo: Atlas, 2010.

GERON, Cecília M. S. Evolução das práticas contábeis no Brasil nos últimos 30 anos: da Lei 6.404/76 à Lei 11.638/07. Dissertação de Mestrado, Faculdade de Economia, Administração e Contabilidade, 2008.

GLEESON-WHITE, Jane. Double entry. Londres: Norton, 2012

IUDÍCIBUS, MARTINS E GELBCKE. Manual de Contabilidade das Sociedades por Ações. São Paulo: Atlas, 1978.

IUDICIBUS, Sérgio et al. Manual de Contabilidade Societária. São Paulo: Atlas, 2010.

IUDÍCIBUS. Teoria da Contabilidade. São Paulo: Atlas, 2000.

NIYAMA, Jorge Katsumi; SILVA, César Augusto Tibúrcio. Teoria da Contabilidade. São Paulo: Atlas, 2011. 
PORTAL DO INVESTIDOR. História do Mercado de Capitais. Disponível em: $<$ http://www.portaldoinvestidor.gov.br/menu/Investidor_Estrangeiro/o_mercado_de_valores_ brasileiros/Historia_Mercado_Capitais.html>. Acesso em 03 mai. 2015.

RIBEIRO, Paulo Silvino. Transformações socioeconômicas no Brasil da década de 50. Disponível em: <http://www.brasilescola.com/sociologia/transformacoessocioeconomicas-no-brasil-decada-50.htm>. Acesso em 27 abr. 2013.

SÁ, Antonio Lopes. História Geral e das Doutrinas da Contabilidade. São Paulo: Atlas, 1997.

SÁ, Antonio Lopes. Pré História Contábil Brasileira. Disponível em: <www.lopesdesa.com.br> Acesso em: 25 abr. 2013.

SANTOS, Antonio R dos. Metodologia Científica. Rio de Janeiro, DP\&A, 2000.

SANTOS, José Luiz dos; SCHMIDT, Paulo. Contabilidade Societária. São Paulo: Atlas, 2002.

SANTOS, Paula Lelaché Cardoso; SOUZA, Patrícia de; WILLMAN, Sthefani Duarte. Características e Mudanças Provocadas pela Lei das Sociedades Anônimas (6.404/76). Disponível: <http://www.trabalhosfeitos.com/ensaios/Caracter\%C3\%ADsticas-eMudan\%C3\%A7as-Provocadas-Pela-Lei/432164.html>. Acesso em: 20 abr. 2013.

SILVA, César Augusto Tibúrcio. História da Contabilidade: Tratado da pratica de Arismética, de Nicolas Gaspar. Contabilidade Financeira <http://www.contabilidadefinanceira.com/2013/06/historia-da-contabilidade-tratado-da.html >, Acesso em novembro de 2013.

SCHMIDT, Paulo. História do pensamento Contábil. Porto Alegre: Bookman, 2000. 